\title{
Reviews
}

\section{New insights into sympathetic regulation of glucose and fat metabolism}

\author{
K. Nonogaki \\ Nina Ireland Laboratory of Developmental Neurobiology, Department of Psychiatry, University of California at San Francisco, \\ San Francisco, California, USA
}

\section{Abstract}

The autonomic nervous system modulates glucose and fat metabolism through both direct neural effects and hormonal effects. This review presents recent concepts on the sympathetic regulation of glucose and fat metabolism. Focally released norepinephrine from sympathetic nerves is likely to increase glucose uptake in skeletal muscle and adipose tissues independent of insulin but norepinephrine does not contribute so much as epinephrine to hepatic glucose production. Epinephrine increases hepatic glucose production and inhibits insulin secretion and the glucose uptake by tissues that is induced by insulin. Additionally, catecholamines can increase thermogenesis and lipolysis, leading to increased energy expenditure and decreased fat stores. It is likely that $\beta$ - $(\beta 3)$ adrenergic receptors mediate these responses. Alterations of central neurotransmission and environmental factors can change the relative contribution of sympathetic outflow to the pancreas, liver, adrenal medulla and adipose tissues, leading to the modula- tion of glucose and fat metabolism. Recent studies have proposed that leptin, an adipocyte hormone, affects the central nervous system to increase sympathetic outflow independent of feeding. The effects of leptin on glucose and fat metabolism could be in part mediated by the sympathetic nervous system. Studies using mice with a genetic disruption of serotonin $5-H T 2 c$ receptor indicate that central neural mechanisms in the regulation of sympathetic outflow and satiety could be dissociated. Abnormalities of sympathetic effects, including disturbances of leptin and $\beta 3$-adrenergic receptor signalling, are likely to cause obesity and impaired glucose tolerance in rodents and humans. These findings indicate that dysfunction of the sympathetic nervous system could predispose to obesity and Type II (non-insulin-dependent) diabetes mellitus. [Diabetologia (2000) 43: 533-549]

Keywords Leptin, sympathetic, adrenergic, glucose, obesity, diabetes.
Corresponding author: K. Nonogaki, MD, PhD, Nina Ireland Laboratory of Developmental Neurobiology, Department of Psychiatry, University of California at San Francisco, 401 Parnassus Avenue San Francisco CA 94143-0984, USA

Abbreviations: CNS, Central nervous system; AR, adrenergic receptor; LPL, lipoprotein lipase; UCP-1, uncoupling protein; PEPCK, phosphoenolpyruvate carboxykinase; LepR, leptin receptor; ARC, arcuate nucleus; $\mathrm{DMH}$, dorsomedial hypothalamic nucleus; PVH, praventricular hypothalamic nucleus; $\mathrm{LH}$, lateral hypothalamic nucleus; VMH, ventromedial hypothalamic nucleus; PK, pyruvate kinase; RVL, rostal ventrolateral medulla; LPGI, lateral paragigantocellular reticular nucleus; BNST, bed nucleus of stria terminals; LSt, lateral septum; SCN, suprachiasmatic nucleus; MPA, medial preoptic area; NPY, neuropeptide Y; POMC, pro-opioidmelanocortin; MC4-R, melanocortin-4R; 5-HT2cR, serotonin 5-HT2 c receptor; i.c. v., intraventricular; DHA, dorsal hypothalamic area.

\section{Background}

Since the observation by Claude Bernard in the $1850 \mathrm{~s}$ that puncture of the floor of the fourth ventricle in dogs results in the appearance of transient glucosuria, the central nervous system (CNS) has been implicated in the control of certain metabolic processes of energy homeostasis mainly through neuroendocrine systems. After its recent discovery, leptin, an adipocyte hormone, has been proposed to signal the CNS to modulate autonomic outflow and food intake, leading to alterations of energy metabolism $[1,2]$. Leptin has been suggested to increase sympathetic outflow and disturbances of leptin signalling lead to 
decreased sympathetic outflow and increased parasympathetic outflow [1-3].

Feeding and increased parasympathetic outflow to the pancreas stimulate insulin secretion, leading to increased energy storage. Insulin increases leptin expression and secretion by white adipose tissue [4-6] Leptin then increases central sympathetic outflow, which leads to suppression of leptin expression in white adipose tissues by $\beta 3$-adrenergic receptors [7]. There could be a negative feedback system between leptin secretion and the sympathetic nervous system. Recent studies using mice with disrupted serotonin 5-HT2 c receptors have indicated that central neural mechanisms in the regulation of feeding and autonomic outflow are not always in parallel and a dysfunction of autonomic neural circuits rather than feeding behaviour could be the primary causative factor in obesity [8]. These autonomic neural circuits could therefore play an important part in the regulation of energy metabolism in addition to the CNS regulation of food intake.

Leptin has also been proposed to modulate hypothalamic pituitary adrenal, thyroid as well as gonadal axes [9-12]. In contrast to these humoral factors, the role of leptin and the autonomic nervous system in the regulation of glucose and fat metabolism is not well understood. The aims of this review are to present recent concepts of autonomic neural regulation of glucose and fat metabolism and to present the role of the sympathetic nervous system in mediating the effects of leptin on glucose and fat metabolism. In addition, this review will provide new insights into the role of the sympathetic nervous system in the pathogenesis and treatment of obesity and Type II (non-insulin-dependent) diabetes mellitus.

\section{Autonomic neural function on metabolic organs}

The autonomic nervous system innervates and regulates the physiological function of important tissues in energy metabolism. The liver is a major metabolic organ for the production of glucose and lipids, and is richly innervated by the autonomic components from the splanchnic sympathetic nerves and vagal parasympathetic nerves [13-15]. The hepatic parenchymal cells are well supplied with nerve fibres of a sympathetic and parasympathetic nature. The pancreas is innervated by the sympathetic and parasympathetic nervous system. Sympathetic and parasympathetic nerve fibres are close to all islet cell types and glucagon and insulin secretion alter in response to pancreatic nerve stimulation. Activation of the splanchnic sympathetic nerves increases glucagon secretion from pancreatic alpha cells and activation of the vagal parasympathetic nerves increases insulin secretion [14]. The adrenal medulla is innervated by typical cholinergic preganglionic sympathetic neu- rons carried in the splanchnic nerves. The adrenal medulla is composed almost entirely of chromaffin cells which contain large amounts of either norepinephrine or epinephrine: in humans $85 \%$ of the adrenomedullary catecholamine store is epinephrine [16]. Skeletal muscle and adipose tissues are major sites of glucose utilisation stimulated by insulin action. Sympathetic and parasympathetic nerves also innervate skeletal muscle. Adipose tissues contain sympathetic innervation and have adrenergic receptors but they do not contain parasympathetic innervation $[16,17]$.

The effects of the sympathetic nervous system on glucose and lipid metabolism are probably mediated by circulating epinephrine, glucagon and the direct sympathetic innervation of the liver, adipose tissues and skeletal muscle. The effects of the parasympathetic nervous system on glucose and lipid metabolism are probably mediated by insulin and the direct parasympathetic innervation of the liver. It has been generally recognized that increased sympathetic neural activity produces catabolic effects on glucose and lipid metabolism whereas increased parasympathetic neural activity produces anabolic effects. The effects of direct parasympathetic neural stimulation of liver on hepatic glucose metabolism are, however, much weaker than those of sympathetic neural stimulation [14]. Activation of the splanchnic sympathetic nerves inhibits insulin secretion from pancreatic beta cells. Adipocytes have adrenergic receptors and therefore are affected by sympathetic stimulation but not by the parasympathetic system. Skeletal muscle glucose metabolism is also affected by sympathetic stimulation. The effects of the parasympathetic nervous system are probably mediated by insulin, which can exert anabolic effects on glucose and fat metabolism (Table 1).

The CNS regulates sympathetic and parasympathetic outflow. Pharmacological stimulation of central cholinergic systems has been shown to increase epinephrine, norepinephrine and glucagon secretion through increased sympathetic outflow and inhibit insulin secretion, leading to acute hyperglycaemia [18, 19]. It is well known to increase gastric acid secretion and decrease heart rate by increased vagus nerve activity. In adrenalectomized rats, pharmacological stimulation of the central cholinergic system increases plasma insulin concentrations also by increased vagus nerve activity [20]. These findings indicate that stimulation of the central cholinergic system increases both sympathetic and parasympathetic outflow but epinephrine is likely to mask insulin secretion mediated by vagus nerve and actions, leading to acute hyperglycaemia.

Thus, both the sympathetic and parasympathetic nerves innervate the liver, pancreas and skeletal muscle but adipose tissues receive only sympathetic innervation and have adrenergic receptors. Parasympa- 
Table 1. The direct autonomic neural effects on glucose and fat metabolism

\begin{tabular}{|c|c|c|}
\hline $\begin{array}{l}\text { Neurotrans- } \\
\text { mitters }\end{array}$ & $\begin{array}{l}\text { Sympathetic } \\
\text { effects } \\
\mathrm{NE}\end{array}$ & $\begin{array}{l}\text { Parasympathetic } \\
\text { effects } \\
\text { Ach }\end{array}$ \\
\hline Liver & $\begin{array}{l}\text { Increase } \\
\text { Glycogenolysis }(\alpha \text { or } \beta) \\
\text { Gluconeogenesis }\end{array}$ & $\frac{\text { Increase }}{\text { Glucogenesis }(\mathrm{M})}$ \\
\hline Muscle & $\begin{array}{l}\text { Increase } \\
\text { Glucose uptake }(\beta) \\
\text { Glycogenolysis }(\beta) \\
\text { LPL activity }(\beta)\end{array}$ & \\
\hline WAT & $\begin{array}{l}\frac{\text { Increase }}{\text { Glucose uptake }(\beta: \beta 3)} \\
\text { Lipolysis }(\beta: \beta 3) \\
\text { Decrease } \\
\text { LPL activity }(\beta) \\
\text { Leptin mRNA expression } \\
(\beta: \beta 3)\end{array}$ & \\
\hline BAT & $\begin{array}{l}\text { Increase } \\
\text { Glucose uptake }(\beta: \beta 3) \\
\text { Thermogenesis }(\beta: \beta 3) \\
\text { LPL mRNA expression }(\beta: \beta 3)\end{array}$ & \\
\hline
\end{tabular}

NE: norepinephrine, Ach: acetylcholine, (): receptor subtype, M: muscarinic receptor, $\alpha, \beta$ : adrenergic receptor, WAT: white adipose tissue, BAT: brown adipose tissue

thetic effects are mediated by direct neural stimulation and insulin, which can be masked by activation of the sympathetic nervous system. The effects of the sympathetic nervous system on glucose and fat metabolism can therefore prevail over those of the parasympathetic nervous system.

\section{Sympathetic effects on glucose and fat metabolism}

Effects of the sympathetic nervous system on hepatic glucose production. Glucose is a major energy source of cell activity and is produced mainly by the liver. The sympathetic nervous system modulates both hepatic glucose production and glucose uptake in peripheral tissues. The sympathetic nervous system promotes hepatic glucose production by activating glycogenolysis in fed states and accelerating gluconeogenesis in fasted states. Hepatic glucose metabolism is under the direct control of hepatic autonomic innervation $[13,14,21]$. Electrical stimulation of the peripheral end of the left splanchnic nerve of rabbits produces rapid increases in the activities of liver enzymes. These enzymes catalyse the rate-limiting steps in glycogen breakdown, such as glycogen phosphorylase and glucose-6-phosphatase, with a concomitant decrease in liver glycogen content. The activity of liver glycogen synthase, the rate-limiting enzyme involved in converting glucose-6-phosphate to glycogen, was, however, greatly increased by electrical stimulation of the peripheral end of the vagus nerve but was slightly decreased by splanchnic nerve stimulation in rabbits [14]. In perfused rat liver, activation of the sympathetic liver nerves causes increases in glucose release and the activity of glycogen phosphorylase and a decrease in the activity of glycogen synthase. In addition, sympathetic stimulation decreases the flow and elicits an intrahepatic redistribution as well as a mobilisation of blood by the closing of sinusoids [13]. Activation of parasympathetic nerves enhances glucose utilisation and causes re-opening of previously closed sinusoids. The actions of hepatic nerves are modulated by hormones including glucagon, insulin, epinephrine and norepinehrine [13]. In humans, subjects who have had liver transplants have normal postabsorptive glucose metabolism and a glucose and insulin challenge elicit a normal response at both hepatic and peripheral sites. Nevertheless, a minimal alteration of endogenous glucose production, increased concentration of insulin and glucagon, and defective counterregulation during hypoglycaemia could reflect an alteration in the liverCNS-pancreatic islet circuit which is due to denervation of the transplanted graft [21].

In addition to the direct effects of innervation of the liver on hepatic glucose production, adrenal medullary epinephrine release and sympathetic response to pancreatic glucagon release contribute to increased hepatic glucose production [14, 18, 19]. It has been suggested that the relative contribution of these factors to this glucose production can be changed by alterations of central neurotransmission in fed rats whereas epinephrine is the major contributor in fasted rats [18, 19] (Fig.1). Among these factors, epinephrine is the strongest effector of hepatic glucose production. It is essential for CNS-mediated acute hyperglycaemia, because after any central neurochemical stimulation, plasma glucose concentrations are not increased unless those of epinephrine are also increased $[18,19]$. Epinephrine promotes hepatic glucose production by activating glycogenolysis in fed states and accelerating gluconeogenesis in fasted states. In contrast to epinephrine, circulating norepinephrine contributes less to rapid increases in hepatic glycogenolysis [16, 22], although a selective rise in sinusoidal norepinephrine has been recently shown to increase hepatic glucose production by stimulating glycogenolysis [23]. Hepatic gluconeogenesis is responsive to high concentrations of norepinephrine such as can be seen at the sympathetic nerve terminal. The enhancement is due to combined increases in the gluconeogenesis precursors, lactate and glycerol, released by peripheral tissues [22].

Various factors can affect the contribution of adrenergic receptor mechanisms to hepatic glucose production. In vitro, the interaction of epinephrine with $\beta$-adrenergic receptors activates the well-known sequence of adenylcyclase stimulation, generation of cAMP and initiation of the cAMP-dependent enzy- 

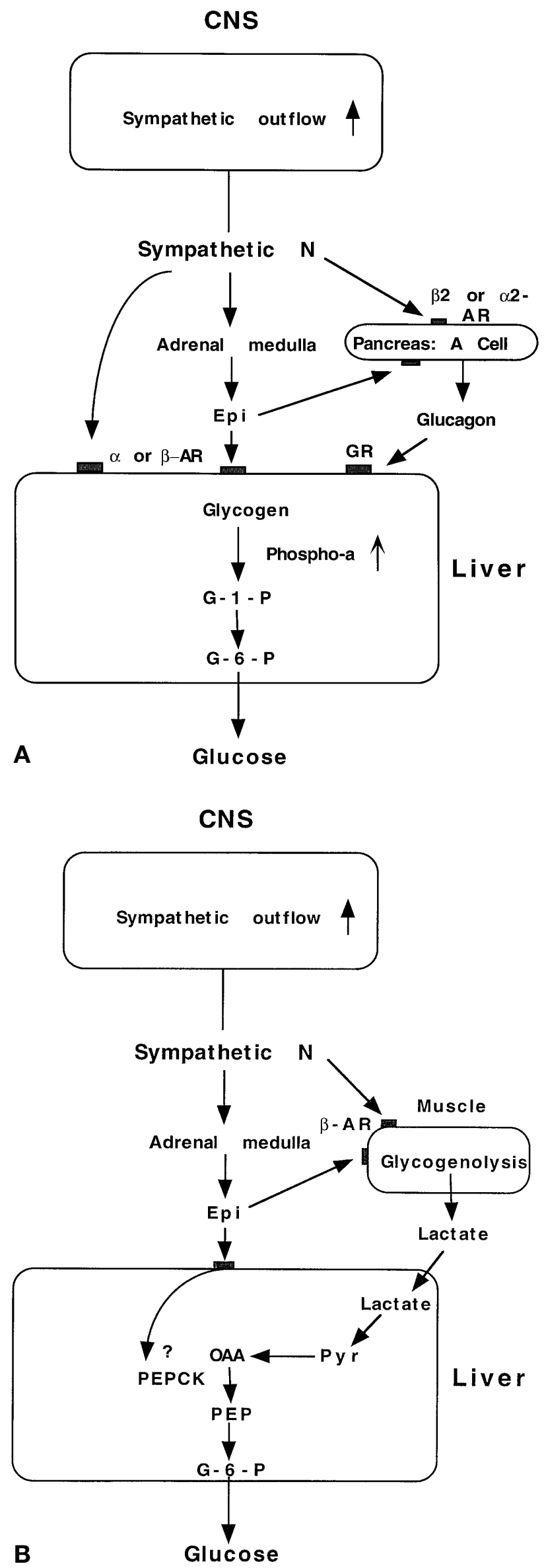

Fig. 1A, B. Possible sympathetic neural pathways involved in the central nervous system-mediated hepatic glucose production. A hepatic glycogenolysis, B hepatic gluconeogenesis. Epinephrine stimulates glucagon secretion and inhibits insulin secretion from pancreas. Epinephrine, glucagon and the direct innervation of liver could contribute to increased hepatic glycogenolysis induced by activation of the central cholinergic system in rats (A). Epinephrine could contribute to increased hepatic gluconeogenesis induced by central cholinergic system in rats (B). Sympathetic N, sympathetic nerve; Epi, epinephrine; AR, adrenergic receptor; GR, glucagon receptor; Phospho-a, phosphorylase-a; G-1-P, glucose-1-phosphate; G-6-P, glucose-6-phosphate; Pyr, pyruvate; OAA, oxaloacetate; PEP, phosphenolpyruvate

matic cascade, leading to conversion of glycogen phosphorylase from the inactive to the active form. Stimulation of the $\alpha$-adrenergic receptors also activates phosphorylase, thereby increasing glycogenolysis in isolated hepatocytes by mechanisms that are independent of cAMP. In rats $\alpha$-adrenergic effects predominate whereas $\beta$-adrenergic effects predominate in dogs $[16,18,19]$. The relative importance of $\alpha$-adrenergic and $\beta$-adrenergic receptors (ARs) in mediating catecholamine-induced hepatic glucose production in humans is still to be resolved.

Pancreatic hormones, which are also regulated by the autonomic nervous system, strongly contribute to changes in hepatic glucose metabolism. Activation of $\beta$-( $\beta 2)$-AR transiently increases secretion of both insulin and glucagon whereas $\alpha-(\alpha 2)$-AR stimulation suppresses insulin secretion [16]. Although the effects of $\alpha-(\alpha 2)$-AR mechanisms on glucagon secretion is still to be resolved, CNS-mediated glucagon secretion has been shown to be enhanced by $\alpha-(\alpha 2)$-AR activation in rats [19]. Inhibition of insulin secretion by $\alpha$ adrenergic receptors usually predominate over its stimulation by $\beta$-adrenergic receptors.

Catecholamines increase muscle glycogenolysis through $\beta$-AR activation using cAMP as the second messenger. Unlike the stimulation in liver, $\alpha$-AR mechanisms do not affect this process in skeletal muscle [16]. Because muscle lacks the enzyme glucose-6phosphatase, the glucose-6-phosphate that is produced by glycogenolysis is metabolised to lactate before it is released into the circulation, leading to hepatic gluconeogenesis. Thus, the receptor mechanisms of the hepatic glucose production induced by catecholamines have often been difficult to interpret because experimental designs did not permit separation of indirect and direct actions.

These findings indicate that the sympathetic nervous system promotes hepatic glucose production at least by direct sympathetic innervation of the liver, adrenal medullary epinephrine and pancreatic glucagon. The relative importance of these pathways and their receptor mechanisms could be changed by a variety of factors including environment, species, diet 
and alterations of neurotransmission. Norepinephrine contributes less to rapid increases in hepatic glucose production than epinephrine.

Effects of the sympathetic nervous system on glucose uptake in skeletal muscle and adipose tissues. Skeletal muscle is considered to be the principal site of insulin-stimulated glucose uptake and a major tissue for blood glucose utilisation. There is, however, also evidence of non-insulin-mediated pathways of glucose utilisation in muscle including sympathetic nerve activity and muscle contraction. Exercise and exposure to cold have been shown to increase skeletal muscle glucose uptake despite unchanged or even reduced plasma insulin concentrations. The alternative mechanisms of glucose uptake are thought to be activated by increased sympathetic activity [16]. Electrical stimulation of the ventromedial hypothalamic nucleus $(\mathrm{VMH})$ and central neurochemical stimulation have shown that the sympathetic nervous system increases glucose uptake in skeletal muscle without an increase in plasma insulin concentration [24-26]. These responses in skeletal muscle are prevented by pretreatment with guanethidine but not by adrenal demedullation, indicating that norepinephrine but not epinephrine is likely to contribute to the responses [25].

In vivo and in vitro, the $\beta$-AR agonists, BRL37344 and BRL35135A, promote glucose transport into skeletal muscle independent of insulin in rats [27, 28]. Glucose transport is the rate-limiting step in glucose utilisation in muscle [29]. To increase glucose transport in muscle, the glucose transporter-4 (GLUT4) is translocated from the intracellular pool to the surface of the muscle by insulin and exercise, albeit by different and largely unknown signalling pathways. The agonist BRL37344 increases glucose transport into L6 myocytes in a dose-dependent manner without affecting the GLUT4 content in the plasma membrane [30]. This indicates that $\beta$-AR stimulation could increase glucose uptake independent of GLUT4 translocation. The $\beta 3$-AR mRNA (or $\beta 3$ AR gene expression) is, however, found primarily in white and brown adipose tissue and is absent from skeletal muscle in rodents and human [31-34]. In addition, CL-316,243, a new $\beta 3$-AR specific agonist, has no effect on skeletal muscle glucose uptake but increases basal and insulin-stimulated glucose uptake by white and brown adipose tissue in non-obese rats [35]. These findings indicate that norepinephrine could enhance glucose uptake in skeletal muscle by $\beta$-AR independent of insulin but it is not known by which subtype of $\beta$-AR.

In contrast to norepinephrine, epinephrine has been considered to inhibit insulin-stimulated glucose uptake in skeletal muscle by $\beta$-AR mechanisms independent of the glucose transport process [16]. Epinephrine lowers glucose transport, possibly by altering the activity of surface GLUT4 transporters and higher concentrations of epinephrine have recently been shown to translocate GLUT4 to plasma membrane associated with increases in muscle cAMP concentration [36, 37]. Epinephrine can translocate GLUT4, leading to increased glucose transport when insulin is absent but can also inhibit glucose transport when insulin is present [38]. Recent studies in vivo have also shown that a physiological increase in plasma epinephrine concentration decreases insulin-stimulated skeletal muscle glycogen synthesis and muscle inorganic phosphate in humans [39].

The sympathetic nervous system also has important effects on glucose uptake in white and brown adipose tissues. Most of the stimulatory effects of the sympathetic nerves on white and brown adipose tissue glucose uptake are based on the $\beta$-adrenergic action of norepinephrine [16]. In vivo, long-term norepinephrine infusion stimulates glucose uptake in white and brown adipose tissue independent of insulin [40]. Long-term treatment with CL-316,243, enhances basal and insulin-stimulated glucose uptake by white and brown adipose tissues without a decrease in body weight and increased non-esterified fatty acid (NEFA) in plasma in non-obese rats [35]. In addition, long-term treatment with CL-316,243 in obese Zucker-ZDF rats increases glucose uptake in skeletal muscle, brown and white adipose tissues associated with improvement of insulin responsiveness and glucose tolerance [41]. In vitro, a non-selective $\beta$-AR agonist, isoproterenol, has been shown to stimulate both GLUT4 translocation and glucose transport at low concentrations by cAMP and to inhibit glucose transport at high concentrations because of an inhibition of the transport activity of surface GLUT4 in white adipocytes [42]. Norepinephrine and BRL37344 by contrast increase glucose transport into brown adipocytes independent of insulin action without stimulating GLUT4 translocation [43]. The intracellular molecular mechanisms through which stimulation by $\beta$-adrenergic modulates glucose transport in skeletal muscle and adipose tissues are still not clear.

Thus, norepinephrine could enhance glucose uptake in skeletal muscle, white adipose tissues and brown adipose tissues independent of insulin whereas epinephrine is believed to inhibit insulin-stimulated glucose uptake in skeletal muscle, independent of the glucose transport process. The $\beta$-ARs, particularly those in adipose tissues, contribute to these processes.

Effects of the sympathetic nervous system on fat metabolism. White adipose tissue is the principal tissue for energy storage in mammals. When energy needs cannot be met by circulating fuels or stored carbohydrate, lipid is mobilised from white adipose tissue 
through the process of lipolysis, a breakdown of triglycerides into glycerol and NEFAs [16]. Physiological evidence strongly suggests that the sympathetic nervous system contributes to the regulation of lipolysis. Although there is no convincing neuroanatomical evidence showing that white adipose tissue is directly innervated by the sympathetic nervous system, the sympathetic innervation of white adipose tissue has recently been proposed to be a part of the general sympathetic nervous system outflow from the CNS, consisting of structures and connections throughout the neural axis [17]. The innervation of white adipose tissue by the sympathetic nervous system could play a part in the regulation of total body fat and lipid mobilisation.

Catecholamines stimulate lipolysis by $\beta$-ARs followed by activation of adenylate cyclase and phosphorylation of the inactive lipase by a cAMP-dependent protein kinase on white adipose tissue but they inhibit lipolysis by $\alpha 2$-ARs $[16,17]$. When $\beta$-AR activation predominates, lipolysis is stimulated and conversely, when $\alpha 2$-AR activation predominates, lipolysis is inhibited $[17,44]$. If lipolysis predominates, then hormone-sensitive lipase, the principal intracellular enzyme responsible for the breakdown of triglycerides into monoacylglycerols, is activated. This enzyme catalyses the first two steps of lipolysis, then monoacylglycerol lipase converts the monoacylglycerols into NEFAs and glycerol in the final step.

Lipoprotein lipase (LPL) is a rate-limiting enzyme that hydrolyses the triglyceride component of circulating lipoproteins. It is bound to glycosaminoglycans on the surface of the endothelium in muscle and white adipose tissue. Catecholamines have been shown to mediate the uptake of triglycerides in both white adipose tissue and muscle in a tissue-specific manner by regulating LPL. In white adipose tissues from rodents and humans, catecholamines inhibit LPL activity and expression by $\beta$-adrenergic receptors whereas in skeletal muscle, catecholamines increase LPL activity [16]. The inhibition of LPL activity by catecholamines in white adipose tissue is posttranscriptional with a strong inhibition of LPL translation [45]. In rat brown adipocytes, norepinephrine increases LPL gene expression through a dominant $\beta 3-\mathrm{AR}$ and an auxillary $\alpha 1-\mathrm{AR}$ pathway [46]. Thus, activation of the sympathetic nervous system could increase lipolysis and decrease triglyceride-rich lipoprotein accumulation into white adipose tissue by $\beta$ ARs leading to decreased fat stores.

Brown adipose tissue is specialised for heat production rather than for fuel storage; it contains mutilobulated fat droplets and large numbers of mitochondria. The brown fat mitochondria are uncoupled during sympathetic stimulation. Energy which is derived from oxidation of fuels is released as heat rather than stored as high-energy phosphate bonds. The sympathetic nerves innervate brown adipose tissue

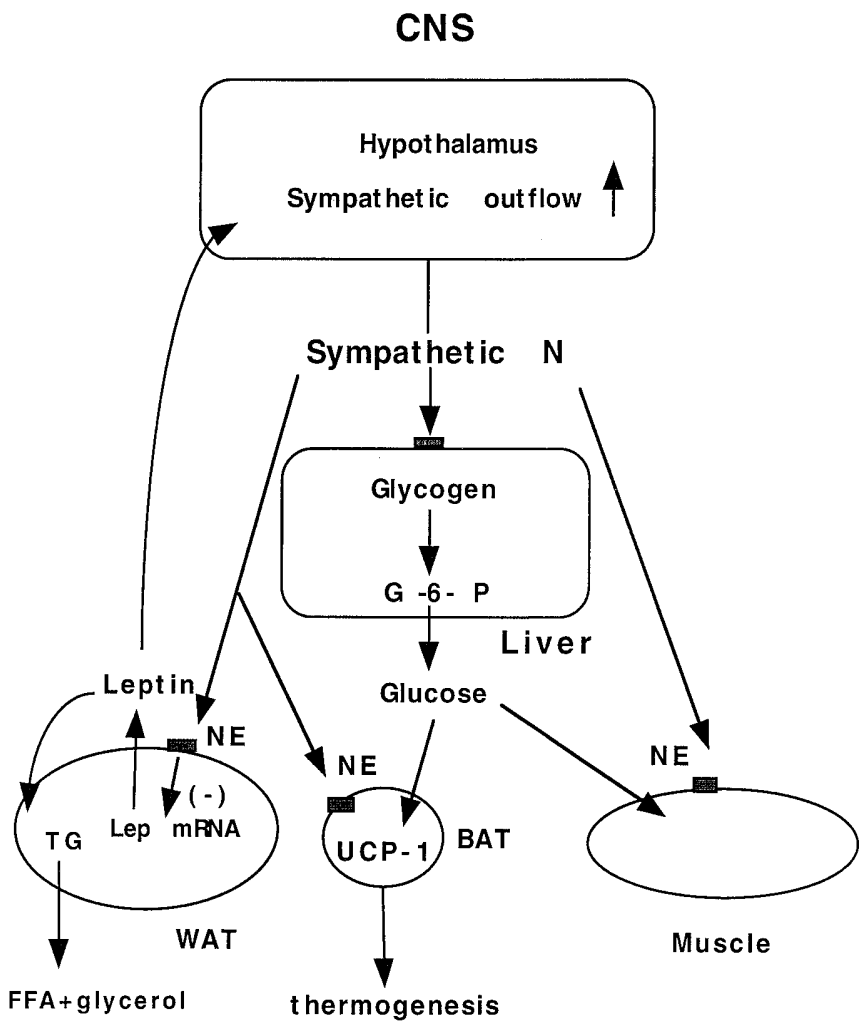

Fig. 2. A hypothesis of neural pathways by which leptin modulates glucose and fat metabolism in vivo. Leptin increases hepatic glycogenolysis and increases glucose uptake in skeletal muscle and brown adipose tissues independent of insulin. Leptin increases the rate of lipolysis and decreases triglycerides content in white adipose tissues. Leptin stimulates brown adipose tissue-induced thermogenesis. Leptin affects the CNS to increase sympathetic outflow. The sympathetic nervous system could mediate these responses in addition to the direct effects of leptin. The increased sympathetic outflow then inhibits leptin mRNA expression in white adipose tissue. Sym. N, sympathetic nerve; WAT, white adipose tissue; BAT, brown adipose tissue; NE, norepinephrine; Lep, leptin; G-6-P, glucose-6-phosphate; TG, triglycerides; (-): inhibition

well and direct neural stimulation promotes heat production by $\beta$-ARs [16]. The brown adipose tissue-specific mitochondrial uncoupling protein (UCP)- 1 in the mitochondrial inner membrane of brown adipose tissue generates heat by uncoupling oxidative phosphorylation. This process protects against cold and regulates energy balance. The CL-316,243 agonist increases UCP-1 expression and protein in brown adipose tissue, resulting in thermogenesis [47].

These findings show that activation of the sympathetic nervous system increases lipolysis, decreases triglyceride-rich lipoprotein accumulation into white adipose tissue and increases thermogenesis in brown adipose tissue, leading to decreased fat stores. The $\beta 3$-AR systems predominately contribute to these processes. 


\section{Effects of leptin on glucose and fat metabolism}

Effects of leptin on hepatic glucose production. Leptin has been shown to have CNS-mediated effects on glucose metabolism independent of its anorectic effect (Fig. 2). In vivo, intravenous (i.v.) infusion of leptin increases hepatic glucose production associated with decreased hepatic glycogen content in lean mice [48]. Similar effects are observed with intraventricular (i.c.v.) injection of leptin. Plasma glucose, insulin and glucagon concentrations are, however, not changed by either i.v. or i.c.v. injection of leptin in lean mice [48]. In addition, i.v. and i.c.v. infusion of leptin has been shown to stimulate hepatic glucose production associated with increased glucose-6-phosphatatse activity and decreased phosphoenolpyruvate carboxykinase (PEPCK) activity in lean rats and $o b / o b$ mice $[49,50]$. These findings indicate that leptin increases hepatic glycogenolysis by the CNS but the CNS-mediated transmitting pathways of leptin to hepatic glucose production have not yet been determined.

Leptin has also been proposed to have direct effects on hepatic glucose metabolism but it is still controversial whether leptin counteracts or mimics insulin action [51-54]. A leptin receptor (LepR) variant has been found in human hepatocellular carinoma cell lines [51]. Exposure of human hepatic cells to leptin, at concentrations similar to those in obese people, caused attenuation of several insulin-induced activities including tyrosine phosphorylation of the insulin receptor substrate-1 (IRS-1), association of the adapter molecule growth factor receptor-bound protein 2 with IRS-1 and down-regulation of gluconeogenesis. In contrast, leptin increased the activity of IRS-1-associated phosphatidylinositol 3-kinase [51]. In isolated perfused rat livers, the effects of shortterm portal leptin infusion on postprandial basal and epinephrine-stimulated glycogenolysis and on postabsorptive lactate-stimulated gluconeogenesis have shown that leptin directly affects hepatic glucose metabolism. The leptin has an insulin-mimicking effect on glycogenolysis and a glucagon-like effect on gluconeogenesis [52]. In addition, in isolated rat hepatocytes, leptin enhances glycogen storage-like insulin action $[53,54]$. The differences between rats and humans could be due to the difference in their cells but in rats the effects of leptin on hepatic glucose metabolism in vitro are not consistent with those in vivo.

The LepR is a member of the gp130 family of cytokine receptors which are known to stimulate gene transcription by activation of the transcription factor, cytosolic STAT protein [1]. Positional cloning of $\mathrm{db}$, the LepR gene, showed that this gene encodes five alternative splice forms. The Ob-Rb variant has a long cytoplasmic region containing several motifs required for signal transduction whereas the other forms lack some or all of these motifs. The effect of leptin is believed to be mediated by the long form of the LepR, Ob-Rb [1]. Within the CNS, leptin's main site of action seems to be in the hypothalamus, including the arcuate nucleus (ARC), dorsomedial hypothalamic nucleus $(\mathrm{DMH})$, periventricular nucleus $(\mathrm{PVH})$, lateral hypothalamus ( $\mathrm{LH})$ and $\mathrm{VMH}$ in which $\mathrm{Ob}-\mathrm{Rb}$ is highly expressed [1]. Leptin induces activation of STAT3 in the hypothalamus of mice within 15 min of intraperitoneal (i.p.) injection but does not induce STAT activation in the liver, adrenal, kidney or lung [55]. These findings indicate that the hypothalamus is a direct target of leptin action and that this activation is critically dependent on LepR. In addition, i.c. v. injection of much smaller amounts of leptin affects hepatic glucose metabolism. Because plasma glucose, insulin and glucagon concentrations are not changed in leptin-treated animals, the sympathetic neural effects on liver by focally released norepinephrine or other mediators could contribute to leptin-induced hepatic glucose production in vivo.

These findings indicate that leptin could increase hepatic glucose production by the hypothalamic lepR in vivo. The sympathetic nervous system could contribute to leptin-induced alterations of hepatic glucose metabolism.

Effects of leptin on glucose uptake in muscle and adipose tissues. Leptin has been shown to increase whole-body glucose utilisation but it also has tissuespecific effects on glucose utilisation. Peripheral and central infusion of leptin increases glucose uptake in brown adipose tissue and muscle, but not in white adipose tissue [48, 56-59]. Leptin up-regulates expression of GLUT4 mRNA and protein in brown adipose tissue but down-regulates it in white adipose tissue without changes in muscle tissues [58]. These effects of leptin are suggested to be mediated by hypothalamic LepR $[1,55]$. The central effect of leptin on glucose uptake in skeletal muscle and brown adipose tissue is considered to be mediated by at least the VMH but not LH in normal rats [56]. The denervation of the sympathetic nerve attenuates the effect of $\mathrm{VMH}$ injection of leptin on glucose uptake in brown adipose tissue and pretreatment with propranolol, a non-specific $\beta$-AR blocker, decreases the enhancement of glucose uptake by tissues [57]. These findings indicate that the effect of leptin is mediated through the $\beta$-adrenergic mechanisms of the sympathetic nerves innervating the tissues. In addition, it seems central leptin and peripheral insulin have a synergistic role in augmenting tissue glucose uptake [57].

Leptin increases insulin sensitivity in normal rats both under fasting conditions and in the presence of hyperinsulinaemia when glucose is clamped independent of altered body weight [60]. In $o b / o b$ mice, i.v. infusion of leptin increased whole-body glucose turnover and stimulated glucose uptake in brown adipose tissue but not skeletal muscle and white adipose tis- 
sue [50]. Leptin treatment in the insulin-deficient diabetic rats restored euglycaemia and substantially improved glucose metabolic rates during the postabsorptive state as well as restoring insulin sensitivities at the levels of the liver and the peripheral tissues during glucose clamp [61]. These findings indicate that the antidiabetic effects of leptin are achieved through both an insulin-independent and an insulinsensitising mechanism.

In isolated mouse soleus and extensor digitorum longus muscle, leptin does not affect insulin-stimulated muscle glycogen synthesis, glucose oxidation or lactate production [62]. In isolated rat adipocytes, leptin impairs insulin action in the physiological concentration range of both leptin and insulin [63]. The presence of small amounts of LepR mRNA has been shown in brown adipose tissue and white adipose tissues but not muscle [64]. These findings indicate that leptin increases glucose utilisation in skeletal muscle and brown adipose tissue but not white adipose tissue possibly through the sympathetic nervous system by focally released norepinephrine.

Effects of leptin on fat metabolism. Leptin increases the rate of lipolysis in white adipose tissue in vivo and in vitro [65-67], leading to a decrease in triglyceride stores. Leptin also decreases triglyceride content in the liver, skeletal muscle and pancreas without increasing plasma NEFA or ketones [65]. The depleted triglyceride content induced by leptin is due to prevent triglyceride formation from NEFA and increased intracellular NEFA oxidation [65]. In addition, leptin treatment for $24 \mathrm{~h}$ increases LPL mRNA in primary cultures of brown adipocytes [66]. The presence of OB-Rb in white and brown adipose tissues has been substantiated by the detection of its transcripts by RT-PCR and leptin treatment in vivo and in vitro activating the Jak/STAT pathway [67]. These effects of leptin are prevented in $f a / f a$ rats with leptin receptor mutation, suggesting that leptin receptor signalling directly contributes to the effect of leptin [67].

Leptin treatment rapidly increases norepinephrine turnover in interscapular brown adipose tissues in $o b /$ $o b$ mice [68]. In wild-type mice leptin treatment does not increase rectal temperature or the activity of UCP-1, although it increases both in $o b / o b$ mice [69]. Leptin treatment does not cause a net increase in 24-h energy expenditure but instead blunts the decreased energy expenditure that generally accompanies food restriction [70]. High doses of leptin and treatment with leptin for 3 days has, however, recently been shown to increase UCP-1 expression in brown adipose tissue and oxygen consumption in normal rats $[71,72]$. This effect is attenuated by denervation, suggesting that leptin-induced enhancement of UCP1 gene expression is dependent on sympathetic innervation [72]. In addition, i.v. infusion of leptin has been shown to gradually increase sympathetic nerve activity in brown adipose tissue, kidney, hindlimb and adrenal medulla [73].

In mice i.c.v. injection of leptin has been shown to increase triiodothyronine and decrease thyroxine, suggesting that leptin treatment increases the rate of conversion of thyroxine to triiodothyronine [48]. Catecholamines affect the rate of deiodination of thyroxine in animals [16]. Other studies found that leptin increases plasma thyroxine concentrations in rats [58] and fasting mice [9]. The relation between leptin and thyroid hormones was not born out in human studies [12]. From these findings, it is still not clear whether interactions between leptin and thyroid hormones by the sympathetic nervous system contribute to alterations in glucose and fat metabolism.

These findings indicate that leptin increases the rate of lipolysis in white adipose tissue and decreases triglyceride content through the sympathetic nervous system and by direct effects through autocrine or paracrine pathways. Leptin probably increases sympathetic stimulation of brown adipose tissue, leading to increased thermogenesis.

\section{Central neural pathways of sympathetic effects on glucose and fat metabolism}

Nerve fibres of the sympathetic nervous system emerge from the spinal cord at the thoracic and lumbar levels whereas parasympathetic fibres emerge from sacral segments of the cord. The cell bodies of these fibres are located in the interomedial lateral nuclei of the spinal cord. These cells are called preganglionic nerve cells and have short axons that innervate cells in ganglia located near the spinal cord. The cells within the ganglia are postganglionic nerve cells that have long axons and synapse with cells in other organ systems. Catecholamine release at the sympathetic nerve endings and the adrenal medulla is a direct consequence of a downward flow of impulses from sympathetic centres within the CNS [16].

Initial studies using electrical stimulation of the hypothalamic nuclei indicated that the VMH is the sympathetic centre and the LH is the parasympathetic centre. The VMH and $\mathrm{LH}$ have been proposed to regulate glucose and fat metabolism in a reciprocal manner [14]. Electrical stimulation of VMH increases the activity of PEPCK, a key gluconeogenic enzyme, and suppresses pyruvate kinase (PK), a key glycolytic enzyme, in rat liver. Electrical stimulation of LH by contrast decreases PEPCK activity without any effect on PK activity [14]. Studies with neurochemical stimulation do not, however, always follow these hypothalamic anatomical boundaries in the neural regulation of energy metabolism. Multiple hypothalamic nuclei around the third cerebral ventricle including the $\mathrm{VMH}, \mathrm{LH}, \mathrm{PVH}$, and medial-preoptic area (MPA) 
seem to enhance sympathetic effects on hepatic glucose metabolism [18, 19].

Recently the viral transneuronal tracing method, Bartha's K strain of the pseudorabies virus, has been used to identify the CNS cell groups that regulate the autonomic outflow systems of pancreas, adrenal medulla, white adipose tissue and brown adipose tissues in rats and Siberian hamsters [74-76]. The $\mathrm{PVH}$, perifornical hypothalamic region $(\mathrm{PeF})$, A5 catecholamine cell group, rostal ventrolateral medulla (RVL) and lateral paragigantocellular reticular nucleus (LPGI) have been proposed to contain a considerable amount of neurons that project to both the sympathetic and parasympathetic pancreatic outflow systems as well as the sympathoadrenal outflow system in rats [74]. In addition, some hypothalamic nuclei including the dorsal hypothalamic area (DHA), $\mathrm{DMH}$ and $\mathrm{LH}$ have been proposed to contain neurons that project to the parasympathetic pancreatic outflow systems. The MPA, DHA, LH and the posterior hypothalamic area have been proposed to contain neurons that project to the sympathetic pancreatic outflow system [74]. Brown adipose tissue is only innervated by sympathetic nerves. The PVH, MPA, LH, suprachiasmatic nucleus (SCN), ARC, bed nucleus of stria terminalis, (BNST) and lateral septum (LS) have been implicated in sympathetic outflow to brown adipose tissue in Siberian hamsters [76]. This distribution of infected neurons in the CNS after pseudorabies virus injections into brown adipose tissue was quite similar to that found after injection into white adipose tissue of Siberian hamsters and rats [75]. Notably, there were little or no neural connections between the VMH and adipose tissues or pancreas using this transneuronal viral tract tracer [74-76] although the VMH has been implicated as a major centre regulating sympathetic outflow systems that alter energy metabolism. One possible reason for this discrepancy is that the targeted stimulation or destruction of the VMH secondarily affected the caudally projecting neurons of the hypothalamic PVH that course near and around the VMH. Alternatively, the pseudorabies virus does not necessarily infect every type of neuron and the possibility remains that these particular neurons are refractory to infection.

Alterations of central neurotransmission have been shown to modulate sympathetic regulation of glucose and fat metabolism (Table 2). A variety of circumstances and afferent factors alter central neurotransmission. The traditional view envisages the sympathetic nervous system and the adrenal medulla working in tandem, with circulating catecholamines from adrenal medulla supporting the effects of the sympathetic nerves. The relation between the sympathetic nervous system and adrenal medulla in the regulation of energy metabolism is, however, more complex. During exposure to cold or physical exercise, for
Table 2. Central neuronal systems involved in the sympathetic regulation of glucose and fat metabolism

\author{
Stimulators \\ Cholinergic system \\ Noradrenergic system \\ Histaminergic system \\ Serotonergic system \\ Corticotropin-releasing factor (CRF) \\ Thyrotropin-releasing hormone (TRH) \\ Bombesin \\ Melanocortin \\ $\beta$-Endorphin \\ Leptin \\ Interleukin-1 \\ $\mathrm{PGF}_{2 \alpha}, \mathrm{PGE}_{2}, \mathrm{PGD}_{2}$ \\ 2-Deoxy-glucose \\ Kainate \\ NMDA \\ L-NMA
}

Inhibitors

$\overline{\text { GABAergic system }}$

Somatostatin analogue

PG: Prostaglandin, NMDA: $N$-methly-D asparate, L-NMA: $N G$-methyl-L-arginine

example, the initial response is predominantly one of sympathetic stimulation but as the severity of the cold or the degree and duration of exertion increases, the secretion of adrenal medullary epinephrine progressively increases. Studies with laboratory animals have indicated that hypoglycaemia, acute hypoxia of a moderate degree and acute ischaemia predominantly stimulate adrenal medullary epinephrine secretion [16]. Humoral factors including glucocorticoid, estrogen and thyroid hormones also affect central neurotransmission which could modulate sympathetic effects $[12,16,77-79]$. It is well known that cross-talk between catecholamines and glucocorticoid-receptor signalling systems can occur and thyroid hormones enhance $\beta$-AR-mediated lipolysis and thermogenesis [12, 16, 77]. Estrogen has been shown to reduce the sympathetic cardiovascular tone in menopausal women [80] and increase the parasympathetic tone of the baroreflexzone in male rats [81]. These interactions between the sympathetic nervous system and humoral factors could be important in regulating sympathetic effects.

Neuropharmacological studies over the past decade indicate that central neural mechanisms regulating adrenal medullary epinephrine release and norepinephrine release from the end of sympathetic nerve terminals could be dissociated [18]. Epinephrine secretion is more likely to have a specific neurochemical regulation in the CNS than norepineprine. Pharmacological stimulation of central cholinergic muscarinic receptors in the VMH, PVH, MPA and LH has been shown to increase hepatic venous plasma glucose concentrations associated with increased epinephrine more than norepinephrine [18, 19]. Cholinergic muscarinic stimulation of the hippocampus 
also increases hepatic venous plasma glucose concentrations associated with increased epinephrine more than norepinephrine. Lesions in the VMH attenuated these responses indicating that the VMH plays a crucial part in the signalling of the hippocampal cholinergic system to stimulate epinephrine secretion and hepatic glucose production $[18,19]$. Pharmacological stimulation of other neurotransmitter systems does not, however, always follow central sympathetic pathways induced by activation of the cholinergic system. Leptin has recently been proposed to act on the VMH but not $\mathrm{LH}$ and PVH to increase sympathetic outflow $[55,56,82]$.

Thus, not only anatomical sites but also different kinds of neurotransmitters contribute to the central regulation of sympathetic outflow. Multiple hypothalamic nuclei around the third cerebral ventricle including the VMH, PVH, MPA and LH probably contribute to sympathetic regulation of glucose and fat metabolism. The relative contribution of sympathetic outflow to pancreas, liver, adipose tissues and adrenal medulla could be changed by alterations of central neurotransmission, environmental and hormonal factors.

\section{Disturbances of sympathetic effects on glucose and fat metabolism}

Electrical and chemical lesions of hypothalamic nuclei. The VMH was initially implicated as a major centre in the regulation of both satiety and sympathetic outflow. Bilateral electrical lesions of VMH cause hyperphagia and hyperinsulinaemia, leading to obesity early after surgery. Vagotomy attenuated the obesity syndrome induced by electrical lesions of the VMH. An increased fat mass was still observed in the animals with VMH lesions under paired feeding conditions [2]. Transplantation of the pancreas attenuates the hyperinsulinaemia and obesity in these lesioned animals [2]. These findings suggest that primary neural innervation of the pancreas plays a central part in the development of hyperphagia and obesity after VMH injury [2].

Chronic intraventricular injection of the orexigenic peptide, neuropeptide Y (NPY) also causes hyperphagia and obesity by a primary neural stimulation of pancreatic insulin secretion [83]. Lesions in the VMH reduce, however, NPY mRNA expression in the hypothalamus [84], indicating that NPY does not contribute to the VMH-lesioned obesity. Rats with lesioned $\mathrm{VMH}$ show an increase in leptin expression and release by white adipose tissue, but they cannot respond to leptin [85]. These findings suggest that increased vagus nerve-pancreatic insulin secretion induced by VMH lesions enhances leptin expression and secretion by white adipose tissue, and that the $\mathrm{VMH}$ is a crucial effector region which leptin acts on. Obesity in the VMH-lesioned animals could result from disturbances of central leptin signalling.

Peripheral injection of gold thioglucose has been used as a model of neurochemical destruction of neurons in the regulation of satiety and sympathetic outflow. Because hypothalamic lesion induced by gold thioglucose absolutely depends on the glucose moiety of gold thioglucose and the presence of insulin and can be blocked by inhibitors of glucose uptake, it is assumed that gold thioglucose specifically damages glucose-responsive neurons including the $\mathrm{VMH}$. The destruction of these glucose-responsive neurons is thought to be the cause of obesity induced by gold thioglucose [86]. Hyperphagia and hyperinsulinaemia were observed at 14 days after injection of gold thioglucose (early stage), leading to obesity and hyperglycaemia at 10 weeks after treatment (late phase) [87]. Obesity induced by gold thioglucose is associated with decreased NPY and pro-opiomelanocortin (POMC), which is the precursor of melanocyte-stimulating hormone (MSH), expression in the hypothalamus $[87,88]$. Thus, such obesity could result from decreased activity of hypothalamic neurons synthesising $\mathrm{POMC}$ but it is also associated with reduced $\mathrm{Ob}-\mathrm{Rb}$ expression in the ARC, VMH, LH and DMH [64], indicating that disturbances of leptin signalling also contribute to obesity induced by gold thioglucose. These findings indicate that there could be an interaction between leptin and POMC signalling.

Effects of functional disruption by colchicine injected in the medial hypothalamic nuclei including $\mathrm{VMH}, \mathrm{PVH}, \mathrm{ARC}$ and DMH on fat stores and hormones have recently been evaluated. Rats with colchicine-induced disruption of VMH, PVH or ARC but not DMH had a similar outcome of obesity associated with increases in plasma insulin and leptin concentrations although $\mathrm{VMH}$ lesions showed a much steeper slope in the relation of leptin to fat mass than sham lesion or any other nuclear lesions [89]. In addition, cholchicine-induced lesions of ARC, PVH and $\mathrm{VMH}$ nuclei all resulted in leptin insensitivity whereas lesions of DMH augmented sensitivity to leptin on weight gain [90]. These findings indicate that the medial hypothalamic cell groups could be necessary for normal leptin responsiveness and the regulation of energy balance.

Thus, studies with electrical and neurochemical lesions in the CNS have indicated that the medial hypothalamus plays an important part in the neural regulation of glucose and fat metabolism. Decreased leptin signalling and POMC activity in the hypothalamus probably contribute to obesity with electrical and neurochemical disruption of cell groups in the hypothalamus of rats. Because electrical and neurochemial lesions do not always block the signalling of neurotransmitters at specific receptors, these approaches have limited evaluation of central interactions of neurotransmitters involved in sympathetic outflow. 


\section{Mice with disruption of a specific neurotransmitter's receptor gene}

Genetic disruption of leptin receptor. The leptin system has been implicated in the regulation of food intake and sympathetic outflow [1]. $d b / d b$ Mice, with a mutated LepR gene (Ob-Rb) have been recognised as a genetic model of perturbed feeding regulation and autonomic outflow. When these animals are as young as 10 to 14 days old, normoglycaemic mice become hyperinsulinaemic. During their first month of life, they are not obese but increase their food intake and show a moderate weight gain. In their second month of life, the $d b / d b$ mice become hyperglycaemic, with blood glucose concentrations reaching as high as $16.5 \mathrm{mmol} / \mathrm{l}$. In parallel, insulin concentrations increase, reaching up to ten times normal values when the animals are 3 months old. In this period the mice gain weight and become very obese. This indicates that disturbances of leptin signalling can cause disturbances of satiety and sympathetic outflow, leading to obesity associated with hyperinsulinaemia induced by increased vagus nerve activity in these animals [2]. $d b / d b$ Mice have hyperglycaemia early in life whereas VMH-lesioned animals do not have hyperglycaemia. Signalling pathways other than the VMH are therefore likely to contribute to the mechanisms of hyperglycaemia in animals with a mutation of the LepR gene. These animals have increased NPY expression and decreased POMC expression in the hypothalamus [91, 92]. In addition, treatment with leptin increases POMC gene expression in the hypothalamus $[93,94]$. These findings indicate that POMC neurons could contribute to alterations of energy metabolism induced by leptin.

Genetic disruption of melanocortin-4 receptor. The melanocortin system has been implicated in regulation of food intake and sympathetic outflow [95]. The melanocortin-4R $(M C 4-R)$ is a $\mathrm{G}$ protein-coupled, seven-transmembrane receptor expressed in the brain. Neurons expressing MC4-Rs localise to the PVH, DMH, and LH [96]. The ectopically expressed agouti protein induces obesity primarily by antagonising the hypothalamic $M C 4-R$ associated with leptin resistance [97-99]. The $\alpha$-melanocytestimulating hormone $(\alpha-\mathrm{MSH})$, derived from the arcuate nucleus POMC neurons, is the primary source of ligand for $M C 4-R$ and appears to have a tonic inhibitory role in feeding and energy storage. Yellow $\left(A^{Y} / \mathrm{a}\right)$ mice have defects in POMC signalling in the brain, leading to obesity associated with leptin resistance [98]. It has been proposed that the weight-reducing effects of leptin are transmitted primarily by way of POMC neurons. The central effects of defective POMC signalling, and the absence of leptin on weight gain in double-mutant lethal yellow $\left(A^{Y} / \mathrm{a}\right)$ leptin-deficient $(o b / o b)$ mice were, however, shown to be inde- pendent and additive. These findings indicate that the obesity is independent of leptin action and resistance to leptin results from desensitisation of leptin signalling [99].

Mice with a mutated $M C 4-R$ gene have hyperphagia, hyperinsulinaemia, maturity-onset obesity and hyperglycaemia which mirrors some characteristic features of the yellow $\left(A^{Y}\right)$ agouti obesity syndrome [100]. Hyperinsulinaemia and hyperphagia could occur almost in parallel, as hyperglycaemia (diabetic range) and hyperinsulinaemia are evident at $10-14$ weeks old in $M C 4-R$ mutant mice [100]. Increased NPY expression in the DMH is observed in $M C 4-R$ mutant mice, indicating that NPY might be a downstream target of POMC neurons [100]. The $A^{Y} / \mathrm{a}$ obese mice did not respond to subcutaneous injection of leptin and were a 100-fold less sensitive to i.c. v. injection of leptin, suggesting that leptin resistance probably results from defects downstream of the leptin receptor in the hypothalamus [64]. Non-obese young adult, $M C-4 R$-deficient mice are resistant to the anorectic effect of MTII, a $\alpha$-MSH-like agonist, suggesting that $\alpha-\mathrm{MSH}$ inhibits feeding primarily by activating MC4-R. Obese MC-4R-deficient mice do not respond to the inhibitory effects of leptin on feeding whereas non-obese $M C 4-R$-deficient mice do [101]. These findings indicate that melanocortin signalling transduced by $M C 4-R$ is not an exclusive target of leptin action and that factors resulting from the obesity syndrome contribute to leptin resistance.

Genetic disruption of serotonin 5-HT2 c receptor. The serotonin system has also been implicated in the regulation of food intake and sympathetic outflow [102104]. The serotonin 5-HT2c receptor $(5-H T 2 c R)$, which is $G$ protein-coupled and expressed in the $\mathrm{CNS}$, contributes to the anorectic effect of m-chlorophenylpiperazine, a non-selective serotonergic agonist [105]. Mice deficient in 5-HT2cR have a late onset of obesity which is probably evident at 8-9 months old [106]. Increased fat mass attenuated in $5-H T 2 c R$ mutants under paired feeding conditions [105]. Despite their hyperphagia, young adult 5$H T 2 c R$-deficient mice are not obese and do not have increased basal plasma insulin concentrations [106]. These findings indicate that the perturbation of satiety in mutants is not associated with the direct neural stimulation of insulin secretion. Hyperinsulinaemia develops in older obese mice (after 8-9 months old) [106], indicating that late-onset hyperinsulinaemia in obese $5-H T 2 c R$-deficient mice is a secondary consequence of the mutation. A mild weight gain occurs without hyperinsulinaemia in 5-HT2cR-deficient mice, indicating that obesity without hyperinsulinaemia induced by increased vagus nerve activity develops very slowly. Older chow-fed mutants are glucose intolerant and have a mild increase in plasma glucose concentrations but not diabetes although 
Table 3. Characteristics of CNS-mediated obesity in mice with a mutated receptor gene

\begin{tabular}{|c|c|c|c|c|}
\hline Mutated receptor & LepR & MC4-R & 5-HT2cR & \\
\hline $\begin{array}{l}\text { Age (weeks) } \\
\text { Leptin sensitivity } \\
\text { SNS } \\
\text { PSNS } \\
\text { Food Intake } \\
\text { Body Mass }\end{array}$ & $\begin{array}{l}8-12 \\
\text { defect } \\
\text { decrease } \\
\text { increase } \\
\text { increase } \\
\text { obesity }\end{array}$ & $\begin{array}{l}10-14 \\
\text { decrease } \\
\text { decrease } \\
\text { increase } \\
\text { increase } \\
\text { obesity }\end{array}$ & $\begin{array}{l}11-14 \\
\text { normal } \\
\text { normal } \\
\text { normal } \\
\text { increase } \\
\text { normal }\end{array}$ & $\begin{array}{l}32-36 \\
\text { a mild decrease } \\
\text { a mild decrease? } \\
\text { a mild increase? } \\
\text { increase } \\
\text { a mild obesity }\end{array}$ \\
\hline $\begin{array}{l}\text { Plasma } \\
\text { Leptin } \\
\text { Insulin } \\
\text { Glucose } \\
\text { Triglycerides } \\
\text { Corticosterone }\end{array}$ & $\begin{array}{l}\text { increase } \\
\text { increase } \\
\text { diabetic } \\
\text { increase } \\
\text { increase }\end{array}$ & $\begin{array}{l}\text { increase } \\
\text { increase } \\
\text { diabetic } \\
? \\
\text { normal }\end{array}$ & $\begin{array}{l}\text { normal } \\
\text { normal } \\
\text { normal } \\
\text { normal } \\
\text { normal }\end{array}$ & $\begin{array}{l}\text { increase } \\
\text { increase } \\
\text { normal } \\
\text { normal } \\
\text { normal }\end{array}$ \\
\hline Glucose tolerance & impaired & impaired & normal & a mild impaired \\
\hline
\end{tabular}

The characteristics are compared in male mice (background of C57BL/six strains). SNS, sympathetic nervous activity, PSNS: parasympathetic activity

high-fat feeding in mutants causes diabetes earlier than in wild-type animals [106].

Young adult 5-HT2cR-deficient mice consume more food despite normal responses to exogenous leptin, indicating that the hyperphagia does not result from a disturbance of leptin signalling but leads to late-onset leptin resistance [106]. In addition, NPY and POMC mRNA expression in the hypothalamus are not changed in hyperphagic young mutants, indicating that neither NPY nor POMC neuronal activity contribute to hyperphagia in $5-H T 2 c R$ mutants (unpublished data). Thus, the obesity syndrome in mice with a mutated 5-HT2cR gene develops in a different manner from $d b / d b$ mice although $5-H T 2 c R$ and $L e p R$ tend to be concentrated in the same hypothalamic areas [1, 107]. Genetic disruption of the 5$H T 2 c R$ probably causes a primary disturbance of satiety regulation rather than a direct neural regulation of glucose and fat metabolism. These findings indicate that central neural mechanisms in the regulation of food intake and autonomic outflow could be dissociated and that hyperphagia without decreased sympathetic outflow and hormonal abnormalities does not rapidly cause obesity (Table 3 ).

Genetic disruption of $\beta 3$-adrenergic receptor and uncoupling protein. The $\beta 3$-AR has been implicated in the regulation of food intake and sympathetic effects on energy metabolism and has been shown to be expressed in brown and white adipose cells where it is coupled to cAMP generation. The treatment of mice with $\beta 3$-AR agonists rapidly inhibits food intake independent of leptin [7], indicating that $\beta 3$-AR signalling could be involved in hypothalamic satiety regulation. Adipocytes from $o b / o b$ mice responded poorly to $\beta$-adrenergic agonists-stimulated adenyl cyclase [108]. In addition, the $\beta 3$-AR mRNA expression is greatly reduced (by 300-fold) in 12-week-old obese $o b / o b$ mice compared with that in lean animals. Expression of $\beta 1$-AR mRNA was also reduced (by four- fold) in $o b / o b$ mice but that of $\beta 2$-AR mRNA was not changed [108].

Mice with a null mutation of the $\beta 3-A R$ gene have a mild increase in fat stores at an early age (21 days) [109]. The effect of CL-316,243, which decreases food intake and increases oxygen consumption and plasma NEFA concentrations, are absent in $\beta 3-A R$ mutant mice $[109,110]$. Furthermore, $\beta 1$-AR mRNA but not $\beta 2$-AR mRNA expression is decreased in the mutants, suggesting that $\beta 1$-adrenergic receptor mRNA expression is up-regulated in white and brown adipose tissues of $\beta 3-A R$ mutant mice [109]. Body fat accumulation develops without hyperphagia at 21 weeks old [110]. These findings suggest that a disturbance of sympathetic neural action on adipose tissues by $\beta 3-A R$ results in an increased fat store without hyperphagia.

Mice lacking mitochondrial uncoupling protein are cold-sensitive but not obese [111], although brown adipose tissue of $U C P$-deficient mice have enlarged lipid vacuoles. Mice deficient in UCP consume less oxygen after treatment with $\beta 3$-AR agonist and they are sensitive to cold, indicating that their thermoregulation is defective. Neither hyperphagia nor obesity develops, however, in UCP-deficient mice. These findings indicate that the sympathetic- $U C P-1$ axis on brown adipose tissue can contribute to thermogenesis but does not contribute to glucose and fat metabolism directly. Factors other than brown adipose tissue-induced thermogenesis could be needed to change glucose and fat metabolism.

\section{Genetic disturbances of sympathetic effects on obesity and diabetes in humans}

Disturbances of leptin secretion and action have recently been implicated in the pathogenesis of human obesity [1]. Plasma leptin concentration correlates with body fat content and is usually increased in 
most obese subjects, suggesting that human obesity is generally associated with an insensitivity to leptin. Although the association of mutations in leptin and its receptor with massive obesity confirms its importance in regulating body weight, these syndromes are rare in humans $[1,112]$. Rather than a primary genetic mutation of leptin production or leptin receptors, secondary perturbation of leptin signalling induced by other factors including chronic hyperphagia, highfat diet or other genetic disturbances could contribute to the more common causes of human obesity.

In contrast to mice with disruption of Lep gene and LepR, mice with disruption of $M C 4-R$ have maturity-onset obesity and hyperglycaemia. Because the development of obesity in MC4-R mutant mice resembles common cases of human obesity which are likely to slowly develop after "middle-age", human $M C 4-R$ gene polymorphisms have recently been evaluated in 190 obese subjects [113]. Three allelic variants were identified, including two new ones, Thr ${ }^{112}$ Met and $I l e^{137}$ Thr. Among 190 subjects screened, 9 were found to be heterozygous for the $M C 4-R$ allelic variants, including 1 for the severely impaired $I l^{137} \mathrm{Thr}$ variant, suggesting that the sequence polymorphism in the MC4-R coding region is probably a common cause of obesity in the cohort studied [113]. Two patients with mutations of POMC have, however, been observed; one was compound heterozygous for two mutations in exon 3 ( $G 7013 T$, $C 7133 \Delta$ ) and the other was homozygous for a mutation in exon 2 (C3804A) which abolished POMC translation. These patients had severe early-onset obesity, adrenal insufficiency and red hair pigmentation [114].

In contrast, a genetic disturbance of sympathetic effects on energy metabolism has recently been identified. Pima Indians have a high frequency of missense mutations of the $\beta 3-A R$ gene (Trp64Arg). Those with the mutation develop early-onset Type II diabetes and tend to have a low metabolic rate [115]. This mutation is also associated with abdominal obesity and resistance to insulin [116, 117], an increased capacity to gain weight [118], a reduced ability to lose weight [119, 120], high BMI [121] and lower lipolytic activities [122]. The frequency of the Arg variant differs, however, between ethnic groups. In Caucasians it is $8-10 \%$, in Japanese about $20 \%$ and as many as $40 \%$ of Alaskan Eskimos have the Arg allele. Homozygotes are rare but they generally occur in a frequency which agrees with the Hardy-Weinberg equilibrium [123]. Recent studies have shown that treatment of lean male subjects with CL-316,243 increases insulin action and fat oxidation (both in a plasma concentration-dependent manner) without affecting heart rate, blood pressure and tremor [124]. This indicates that $\beta 3$-AR signalling could have an important role in the pathogenesis and treatment of obesity and Type II diabetes.
A strong association between obesity and a missense mutation in coden 27 of the $\beta 2-A R$ gene replacing glutamine to glutamic acid (Gln27Glu) has also been reported [125]. The Gln27Glu variant is strongly associated with obesity in women. Women who are homozygous for $27 \mathrm{Glu}$ have an average $20 \mathrm{~kg}$ higher fat mass and about $50 \%$ larger fat cells than control subjects. The Gln27Glu variant of the $\beta 2-A R$ gene could be an important obesity gene polymorphism in women but no data are available for men. These findings indicate that the genetic variability in the $\beta 3-A R$ and $\beta 2-A R$ genes and disturbances of their signalling could be important for the development of human obesity.

\section{Conclusion and a hypothesis}

Since its recent discovery, leptin has been recognised as an afferent pathway from the peripheral organs to the CNS involved in the regulation of energy metabolism. Leptin can be also recognised as an effector of glucose and fat metabolism. The effects of leptin on energy metabolism could be in part mediated by the sympathetic nervous system by locally released norepinephrine-like effects in vivo although leptin has also been shown to act directly in the periphery. Epinephrine and norepinephrine, which are secreted by the adrenal medulla and the sympathetic nerve terminals, have some different effects on glucose metabolism. Epinephrine increases hepatic glucose production and inhibits insulin-induced glucose uptake in skeletal muscle and adipose tissues, leading to a rapid increase in plasma glucose concentration. In contrast, norepinephrine contributes less to hepatic glucose production than epinephrine but could increase glucose uptake and its utilisation in skeletal muscle and adipose tissues by the potent $\beta 3$-adrenergic receptor independent of insulin action. Although the relative importance of the effects of norepinephrine and epinephrine on fat metabolism are still to be resolved, activation of the sympathetic nervous system increases lipolysis and decreases triglyceride-rich lipoprotein accumulation into white adipose tissue by the potent $\beta 3$-adrenergic receptor, leading to decreased fat stores. The direct sympathetic stimulation of brown adipose tissue and $\beta 3$-adrenergic stimulation produce thermogenesis, leading to increased energy expenditure.

In addition to these pharmacological and physiological studies, recent approaches using transgenic mice could provide new insights into the sympathetic nervous system and regulation of energy metabolism. Mice with a genetic disruption of the specific neurotransmitter receptors involved in sympathetic effects are usually obese and have impaired glucose tolerance. The developmental processes are, however, very different. Studies using $5-H T 2 c R$ mutant mice 
indicate that hyperphagia without decreased sympathetic effects and abnormalities of hormones does not rapidly cause obesity. Although central neural mechanisms in the regulation of food intake and autonomic outflow have been recognised to occur in parallel, recent studies indicate that they could be dissociated. The sympathetic nervous system should function properly for increased energy intake to be compensated by increased energy expenditure. Dysfunction of the sympathetic nervous system should therefore be considered, in addition to feeding, as a primary cause of CNS-mediated obesity.

Leptin insensitivity, which is observed in most obese rodents, is associated with decreased sympathetic outflow, leading to obesity and impaired glucose tolerance. Leptin resistance has been recognised as a common pathophysiology of obesity in most humans although mutations of the leptin gene and LepR gene are very rare. Moreover, Pima Indians develop abdominal obesity and early-onset Type II diabetes which have a high frequency of missense mutations of the $\beta 3-A R$ gene (Trp64Arg). The frequency of the $A r g$ variant differs, however, between ethnic groups. Caucasians and Japanese have a low frequency of missense mutations of the $\beta 3-A R$ gene $(8-10 \%$ and about $20 \%$, respectively). These findings indicate that secondary decreased sympathetic effects including a secondary perturbation of leptin and $\beta 3-A R$ signalling could be a cause of human obesity and Type II diabetes.

Thus, the sympathetic nervous system has an important role in the regulation of glucose and fat metabolism. Dysfunction of the sympathetic nervous system regulation of metabolic organs could predispose to obesity and Type II diabetes. Further insights into the mechanisms by which the autonomic nervous system modulates glucose and fat metabolism could therefore provide new insights into the pathophysiology and strategies for the treatment of obesity and diabetes.

Acknowledgements. The author thanks Drs L.H. Tecott, G. Lee, J. Danao, J. Yoon and E. Goulding for critical reading of the manuscript and Drs N. Hotta, N. Sakamoto and A. Iguchi, Department of Internal Medicine III and Geriatrics, Nagoya University School of Medicine, for their encouragement of my work. This work was supported in part by grants from Merck Co.

\section{References}

1. Friedman JM, Halaas JL (1998) Leptin and the regulation of body weight in mammals. Nature 395: 763-770

2. Bray GA, York DA (1998) The MONA LISA hypothesis in the time of leptin. Recent Prog Horm Res 53: 95-118

3. Haynes WG, Sivitz W, Morgan DA, Walsh SA, Mark AL (1997) Sympathetic and cardiorenal actions of leptin. Hypertension 30: 619-623
4. Saladin R, De Vos P, Guerre-Millo M et al. (1995) Transient increase in obese gene expression after food intake or insulin administration. Nature 377: 527-529

5. Biden G, Chen X, Kolaczynski JW, Polansky M (1997) Effects of prolonged hyperinsulinemia on serum leptin in normal human subjects. J Clin Invest 100: 11071113

6. Barr VA, Malide D, Zarnowski MJ, Talor SI, Cushman SW (1997) Insulin stimulates both leptin secretion and production by rat white adipose tissue. Endocrinology 138: 4463-4472

7. Mantzoros CS, Qu D, Frederich RC et al. (1996) Activation of $\beta 3$ adrenergic receptors suppresses leptin expression and mediates a leptin-independent inhibition of food intake in mice. Diabetes 45: 909-914

8. Nonogaki K (1999) Obesity: autonomic circuits versus feeding. Nat Med 5: 742-743

9. Ahima RS, Prabakaran D, Mantzoros C et al. (1996) Role of leptin in the neuroendocrine response to fasting. Nature 382: 250-252

10. Chehab FF, Lim ME, Lu R (1996) Correction of the sterility defect in homozygous obese female mice by treatment with the human recombinant leptin. Nat Genet 12: 318-320

11. Licinio J, Mantzoros C, Negrao AB et al. (1997) Human leptin levels are pulsatile and inversely related to pituitary-adrenal function. Nat Med 3: 575-579

12. Orban Z, Bornstein SR, Chrousos GP (1998) The interaction between leptin and the hypothalamic-pituitary-thyroid axis. Horm Metab Res 30: 231-235

13. Gardemann A, Puschel GP, Jungermann K (1992) Nervous control of liver metabolism and hemodynamics. Eur J Biochem 207: 399-411

14. Shimazu T (1996) Innervation of the liver and glucoregulation: role of the hypothalamus and autonomic nerves. Nutrition 12: 65-66

15. Saxena R, Theise ND, Crawford JM (1999) Microanatomy of the human liver-exploring the hidden interfaces. Hepatology 30: 1339-1346

16. Landsberg L, Young JB (1992) Catecholamines and adrenal medulla. In: Wilson JD, Foster DW (eds) Williams textbook of Endocrinology, 8th edn. W. B. Saunders, Philadelphia, pp 621-706

17. Bartness TJ, Bamshad M (1998) Innervation of mammalian white adipose tissue: implications for the regulation of total body fat. Am J Physiol 275: R1399-R1411

18. Nonogaki K, Iguchi A (1997) Role of central neural mechanisms in the regulation of hepatic glucose metabolism. Life Sci 60: 797-807

19. Nonogaki K, Iguchi A (1997) Stress, acute hyperglycemia and hyperlipidemia: role of autonomic nervous system and cytokines. Trends Endocrinol Metab 8: 192-197

20. Gotoh M, Iguchi A, Yatomi A et al. (1989) Vagally mediated insulin secretion by stimulation of brain cholinergic neurons with neostigmine in bilateral adrenalectomized rats. Brain Res 493: 97-102

21. Perseghin G, Regalia E, Battezzati A et al. (1997) Regulation of glucose homeostasis in humans with denervated livers. J Clin Invest 100: 931-941

22. Chu C, Sindelar DK, Neal DW, Allen EJ, Donahue EP, Cherrington AD (1998) Effect of a selective rise in sinusoidal norepinephrine on HPG is due to an increase in glycogenolysis. Am J Physiol 274: E162-E171

23. McGuinness OP, Shau V, Benson EM et al. (1997) Role of epinephrine and norepinephrine in the metabolic response to stress hormone infusion in the conscious dog. Am J Physiol 273: E674-E681 
24. Sudo M, Minokoshi Y, Shimazu T (1991) Ventromedial hypothalamic stimulation enhances peripheral glucose uptake in anesthetized rats. Am J Physiol 261: E298-E303

25. Minokoshi Y, Okano Y, Shimazu T (1994) Regulatory mechanism of the ventromedial hypothalamus in enhancing glucose uptake in skeletal muscles. Brain Res 649: 343-347

26. Lang CH, Ajmal M, Baillie AGS (1995) Neural control of glucose uptake by skeletal muscle after central administration of NMDA. Am J Physiol 268: R492-R497

27. Abe H, Minokoshi Y, Shimazu T (1993) Effect of a $\beta 3$ adrenergic agonist, BRL35135A, on glucose uptake in rat skeletal muscle in vivo and in vitro. J Endocrinol 139: 479-486

28. Liu YL, Cawthorne MA, Stock MJ (1996) Biophagic effects of the $\beta$-adrenoceptor agonist, BRL 37344, on glucose utilization in rat isolated skeletal muscle. Brit J Pharmacol 117: 1355-1361

29. Klip A, Marette A (1992) Acute and chronic signals controlling glucose transport in muscle. J Cell Biochem 48: $51-60$

30. Tanishita T, Shimazu Y, Minokoshi Y, Shimazu T (1997) The $\beta 3$-adrenergic agonist BRL37344 increases glucose transport into L6 myocytes through a mechanism different from that of insulin. J Biochem (Tokyo) 122: 90-95

31. Granneman JG, Lahners KN, Chaudhry A (1991) Molecular cloning and expression of the rat $\beta 3$-adrenergic receptor. Mol Pharmacol 40: 895-899

32. Lelias JM, Kaghad M, Rodriguez M et al. (1993) Molecular cloning of a human $\beta 3$-adrenergic receptor cDNA. FEBS Lett 324: 127-130

33. Muzzin P, Revelli JP, Kuhne F et al. (1991) An adipose tissue-specific $\beta$-adrenergic receptor. J Biol Chem 266: 24053-24058

34. Krief A, Lonnquist F, Raimbault S et al. (1993) Tissue distribution of $\beta 3$-adrenergic receptor mRNA in man. J Clin Invest 91: 344-349

35. De Souza CJ, Hirshman MF, Horton ES (1997) CL316,243 , a $\beta 3$-specific adrenoceptor agonist, enhances insulin-stimulated glucose disposal in nonobese rats. Diabetes 46: $1257-1263$

36. Bonen A, Megeney LA, McCarthy SC, McDermott JC, Tan MH (1992) Epinephrine administration stimulates GLUT4 translocation but reduces glucose transport in muscle. Biochem Biophys Res Commun 187: 685-691

37. Han X-X, Bonen A (1998) Epinephrine translocates GLUT-4 but inhibits insulin-stimulated glucose transport in rat muscle. Am J Physiol 274: E700-E707

38. Laurent D, Petersen KF, Russell RR, Cline GW, Shulman GI (1998) Effect of epinephrine on muscle glycogenolysis and insulin-stimulated muscle glycogen synthesis in humans. Am J Physiol 274: E130-E138

39. Jones JP, Dohm L (1997) Regulation of glucose transporter GLUT-4 and hexokinase II gene transcription by insulin and epinephrine. Am J Physiol 273: E682-E687

40. Liu X, Perusse F, Bukowiecki LJ (1994) Chronic norepinephrine infusion stimulates glucose uptake in white and brown adipose tissues. Am J Physiol 266: R914-R920

41. Kiu X, Perusse F, Bukowiecki LJ (1998) Mechanisms of the antidiabetic effects of the $\beta 3$-adrenergic agonist CL316243 in obese Zucker-ZDF rats. Am J Physiol 274: R1212-R1219

42. Macaulay SL, Kelada ASM, Proietto J (1994) Isoproterenol inhibits cyclic AMP-mediated but not insulin-mediated translocation of the Glut-4 glucose transporter isoform. Mol Cell Biochem 141: 27-33
43. Shimizu Y, Kielar D, Minokoshi Y, Shimazu T (1996) Noradrenaline increases glucose transport into brown adipocytes in culture by a mechanisms different from that of insulin. Biochem J 314: 485-490

44. Lafontan M, Berlan M (1995) Fat cell $\alpha 2$-adrenocpetors: the regulation of fat cell function and lipolysis. Endocr Rev 1: 716-738

45. Yurht A, Davis RC, Ong JM, Ranganathan G, Kern PA (1995) Regulation of lipoprotein lipase translation by epinephrine in 3T3-L1 cells importance of the 3 ' untranslated region. J Clin Invest 96: 2438-2444

46. Kuusela P, Rehnmark S, Jacobsson A, Cannon B, Nedergaard J (1997) Adrenergic stimulation of lipoprotein lipase gene expression in rat brown adipocytes differentiated in culture: mediation via $\beta 3$ - and $\alpha 1$-adrenergic receptors. Biochem J 321: 759-767

47. Himms-Hagen J, Cui J, Danforth E Jr et al. (1994) Effect of CL-316, 243, a thermogenic $\beta 3$-agonist, on energy balance and brown and white adipose tissues in rat. Am J Physiol 266: R1371-R1382

48. Kamohara S, Burcelin R, Halaas JL, Friedman JM, Charron MJ (1997) Acute stimulation of glucose metabolism in mice by leptin treatment. Nature 389: 374-377

49. Liu L, Karkanias GB, Morales JC et al. (1998) Intracerebroventricular leptin regulates hepatic but not peripheral glucose fluxes. J Biol Chem 47: 31160-31167

50. Burcelin R, Kamohara S, Li J, Tannenbaum GS, Charron MJ, Friedman JM (1999) Acute intravenous leptin infusion increases glucose turnover but not skeletal muscle glucosae uptake in ob/ob mice. Diabetes 48: 1264-1269

51. Cohen B, Novick D, Rubinstein M (1996) Modulation of insulin activities by leptin. Science 274: 1185-1188

52. Nemecz M, Preinneger K, Englisch R et al. (1999) Acute effect of leptin on hepatic glycogenolysis and gluconeogenesis in perfused rat liver. Hepatology 29: 166-172

53. Berti L, Kellerer M, Capp E, Haring HU (1997) Leptin stimulates glucose transport and glycogen synthesis in C2C12 myotubes: evidence for PI-3-kinase-mediated effect. Diabetologia 40: 606-609

54. Aiston S, Agius L (1999) Leptin enhances glycogen storage in hepatocytes by inhibition of phosphorylase and exerts an additive effect with insulin. Diabetes 48: 15-20

55. Vaisse C, Halaas JL, Horvath CM, Darnell JE Jr, Stoffel M, Friedman JM (1996) Leptin activation of Stat3 in the hypothalamus of wild type and ob/ob mice but not $\mathrm{db} / \mathrm{db}$ mice. Nat Genet 14: 95-97

56. Minokoshi Y, Shahidul M, Shimazu T (1999) Microinjection of leptin into the ventromedial hypothalamus increases glucose uptake in peripheral tissues in rats. Diabetes 48: 287-291

57. Haque MS, Minokoshi Y, Hamai M, Iwai M, Horiuchi M, Shimazu T (1999) Role of the sympathetic nervous system and insulin in enhancing glucose uptake in peripheral tissues after intrahypothalamic injection of leptin in rats. Diabetes 48: 1706-1712

58. Wang J-L, Chinookoswong N, Scully S, QI M, Shi Z-G (1999) Differential effects of leptin in regulation of tissue glucose utilization in vivo. Endocrinology 140: 2117-2124

59. Rouru J, Cusin I, Zakrzewska KE, Jeanrenaud B, Rohner-Jeanrenaud F (1999) Effects of intravenously infused leptin on insulin sensitivity and on the expression of uncoupling proteins in brown adipose tissue. Endocrinology 140: 3688-3692

60. Sivitz WI, Walsh SA, Morgan DA, Thomas MJ, Haynes WG (1997) Effects of leptin on insulin sensitivity in normal rats. Endocrinology 138: 3395-3401 
61. Chinookoswong N, Wang J-L, Shi Z-Q (1999) Leptin restores euglycemic and normalizes glucose turnover in insulin-deficient diabetes in the rat. Diabetes 48: 14871492

62. Muoio DM, Dohn GL, Friedorek FT Jr, Tapscott EB, Coleman RA (1997) Leptin directly alters lipid partitioning in skeletal muscle. Diabetes 46: 1360-1363

63. Muller G, Ertl J, Gerl M, Preibisch G (1997) Leptin impairs metabolic actions of insulin in isolated rat adipocytes. J Biol Chem 272: 10585-10593

64. Fei H, Okano HJ, Li C et al. (1997) Anatomic localization of alternatively spliced leptin receptors $(\mathrm{Ob}-\mathrm{R})$ in mouse brain and other tissues. Proc Natl Acad Sci USA 94: 7001-7005

65. Shimabukuro M, Koyama K, Chen G et al. (1997) Direct antidiabetic effect of leptin through triglyceride depletion of tissues. Proc Natl Acad Sci USA 94: 4637-4641

66. Siegrist-Kaiser CA, Pauli V, Juge-Aubry CE et al. (1997) Direct effects of leptin on brown and white adipose tissue. J Clin Invest 100: 2858-2863

67. Fruhbeck G, Aguado M, Martinez JA (1997) In vitro lipolytic effect of leptin on mouse adipocytes: evidence for a possible autocrine/paracrine role of leptin. Biochem Biophys Res Commun 240: 590-594

68. Collins S, Kuhn CM, Petro AE, Swick AG, Chrunyk BA, Surwit RS (1996) Role of leptin in fat regulation. Nature 380: 677

69. Harris RBS, Zhou J, Redmann SM Jr et al. (1998) A leptin dose-response study in obese (ob/ob) mice and lean $(+/$ ?) mice. Endocrinology 139: 8-19

70. Halaas JL, Boozer C, Blair-West J, Fidahusein N, Denton DA, Friedman JM (1997) Physiological response to longterm peripheral and central leptin infusion in lean and obese mice. Proc Natl Acad Sci USA 94: 8878-8883

71. Scarpace PJ, Matheny M, Pollock BH, Tumer N (1997) Leptin increases uncoupling protein expression and energy expenditure. Am J Phsyiol 273: E226-E230

72. Scarpace PJ, Matheny M (1998) Leptin induction of UCP1 gene expression is dependent on sympathetic innervation. Am J Physiol 275: E259-E264

73. Haynes WG, Morgan DA, Walsh SA, Mark AL, Sivitz WI (1997) Receptor-mediated regional sympathetic nerve activation by leptin. J Clin Invest 100: 270-278

74. Jansen ASP, Loewy HAD (1997) CNS sites involved in sympathetic and parasympathetic control of the pancreas: a viral tracing study. Brain Res 766: 29-38

75. Bamshad M, Song CK, Bartness TJ (1999) CNS origins of the sympathetic nervous system outflow to brown adipose tissue. Am J Physiol 276: R1569-R1578

76. Bamshad M, Aoki VT, Adkison MG, Warren WS, Bartness TJ (1998) Central nervous system origins of the sympathetic nervous system outflow to white adipose tissue. Am J Physiol 275: R291-R299

77. McEwen BS (1998) Protective and damaging effects of stress mediators. N Engl J Med 338: 171-179

78. McEwen BS (1999) Estrogen actions in the central nervous system. Endocr Rev 20: 279-307

79. McEwen BS (1999) The molecular and neuroanatomical basis for estrogen effects in the central nervous system. J Clin Endocrinol Metab 84: 1790-1797

80. Del Rio G, Velardo A, Menozzi R et al. (1998) Acute estradiol and progesterone administration reduced cardiovascular and catecholamine responses to mental stress in menopausal women. Neuroendocrinology 67: 269-274

81. Saleh TM, Connell BJ (1999) Centrally mediated effect of $17 \beta$-estradiol on parasympathetic tone in male rats. Am J Physiol 276: R474-R481
82. Satoh N, Ogawa Y, Katsuura G et al. (1999) Sympathetic activation of leptin via the ventromedial hypothalamus. Leptin-induced increase in catecholamine secretion. Diabetes 48: 1787-1793

83. Sainsbury A, Rohner-Jeanrenaud F, Cusin I et al. (1997) Chronic central neuropeptide $\mathrm{Y}$ infusion in normal rats: status of the hypothalamo-pituitary-adrenal axis, and vagal mediation of hyperinsulinemia. Diabetologia 40: 1269-1277

84. Dube MG, Xu B, Kalra PS, Sninsky CA, Kalra SP (1999) Disruption in neuropeptide $\mathrm{Y}$ and leptin signaling in obese ventromedial hypothalamic-lesioned rats. Brain Res 816: 38-46

85. Satoh N, Ogawa Y, Katsuura G et al. (1997) Pathophysiological significance of the obese gene product, leptin, in ventromedial hypothalamus (VMH)-lesioned rats: evidence for loss of its satiety effect in $\mathrm{VMH}$-lesioned rats. Endocrinology 138: 947-954

86. Bergen HT, Monkman N, Mobbs CV (1996) Injection with gold thioglucose impairs sensitivity to glucose: evidence that glucose-responsive neurons are important for longterm regulation of body weight. Brain Res 734: 332-336

87. Marks JL, Waite K, Cameron-Smith D, Blair SC, Cooney GJ (1996) Effects of glold thioglucose on neuropeptide Y messenger RNA levels in the mouse hypothalamus. Am J Physiol 270: R1208-R1214

88. Bergen HT, Mizuno TM, Taylor J, Mobbs CV (1998) Hyperphagia and weight gain after gold-thioglucose:realtion to hypothalamic neuropeptide Y and proopiomelanocortin. Endocrinology 139: 4483-4488

89. Choi S, Dallman MF (1999) Hypothalamic obesity: multiple routes mediated by loss of function in medial cell groups. Endocrinology 140: 4081-4088

90. Choi S, Sparks R, Clay M, Dallman MF (1999) Rats with hypothalamic obesity are insensitive to central leptin injections. Endocrinology 140: 4426-4433

91. Kesterson RA, Huszar D, Lynch CA, Simerly RB, Cone RD (1997) Induction of neuropeptide Y gene expression in the dorsal medial hypothalamic nucleus in two models of the agouti obesity syndrome. Mol Endocrinol 11: 630-637

92. Mizuno TM, Kleopoulos SP, Bergen HT, Roberts JL, Priest CA, Mobbs CV (1997) Hypothalamic pro-opiomelanocortin mRNA is reduced by fasting in ob/ob and db/db mice, but is stimulated by leptin. Diabetes 47: 294-297

93. Schwartz MW, Seeley RJ, Woods SC et al. (1997) Leptin increases hypothalamic pro-opiomelanocortin mRNA expression in the rostral arcuate nucleus. Diabetes 46: 2119-2123

94. Hakansson M-L, Brown H, Ghilardi N, Skoda RC, Meister B (1998) Leptin receptor immunoreactivity in chemically defined target neurons of the hypothalamus. J Neurosci 18: 559-572

95. Haynes WG, Morgan DA, Djalai A, Sivitz WI, Mark AL (1999) Interactions between the melanocortin system and leptin in control of sympathetic nerve traffic. Hypertension 33: 542-547

96. Lu D, Willard D, Patel IR et al. (1994) Agouti protein is an antagonist of the melanocyte-stimulating hormone receptor. Nature 371: 799-802

97. Mountjoy KG, Mortrud MT, Low MJ, Simerly RB, Cone RD (1994) Localization of the melanocortin-4 receptor (MC4-R) in neuroendocrine and autonomic control circuits in the brain. Mol Endocrinol 8: 1298-1308

98. Fan W, Boston BA, Kesterson RA, Hruby VJ, Cone RD (1997) Role of melanocortinergic neurons in feeding and the agouti obesity syndrome. Nature 385 : 165-168 
99. Boston BA, Blaydon KM, Varnerin J, Cone RD (1997) Independent and additive effects of central POMC and leptin pathways on murine obesity. Science 278: 1641-1644

100. Huszar D, Lynch CA, Fairchild-Huntress V et al. (1997) Targeted disruption of the melanocortin-4 receptor results in obesity in mice. Cell 88: 131-141

101. Marsh DJ, Hollopeter G, Huszar D et al. (1999) Response of melanocortin-4 receptor-deficient mice to anorectic and orexigenic peptides. Nat Genet 21: 119-122

102. Chaouloff F (1993) Physiolpharmacological interactions between stress hormones and central serotonergic systems. Brain Res Brain Res Rev 18: 1-32

103. Boetoo S, Richard D (1995) Functional assesment of the 5HT1A-, 1B-, 2A/2C-, and 3-receptor subtypes on food intake and metabolic rate in rats. Am J Physiol 37: R14-R20

104. Sugimoto Y, Yamada J, Yoshikawa T, Horisaka K (1996) Effects of the 5-HT2 c/2B receptor agonist 1-(3-chlorophenyl) piperazine on plasma glucose level of rats. Eur J Pharmacol 307: 75-80

105. Tecott LH, Sunn LM, Akana SF et al. (1995) Eating disorder and epilepsy in mice lacking 5-HT2 c receptors. Nature 374: 542-546

106. Nonogaki K, Strack AM, Dallman MF, Tecott LH (1998) Leptin-independent hyperphagia and type 2 diabetes in mice mutated serotonin 5-HT2 c receptor gene. Nat Med 4: 1152-1156

107. Wright DE, Seroogy KB, Lundgren KH, Davis BM, Jennes L (1995) Comparative localiztion of serotonin $1 \mathrm{~A}, 1 \mathrm{C}$ and 2 receptor subtype mRNAs in rat brain. J Comp Neurol 351: 357-373

108. Susulic VS, Frederich RC, Iwaitts J et al. (1995) Targeted disruption of the $\beta 3$-adrenergic receptor gene. J Biol Chem 270: 29483-29492

109. Collins S, Daniel KW, Rohlfs EM, Ramkumar V, Taylor IL, Gettys TE (1994) Impaired expression and functional activity of the $\beta 3$ and $\beta 1$-adrenergic receptors in adipose tissue of congenitally obese (C57BL/6J ob/ob) mice. Mol Endocrinol 8: 518-527

110. Revelli J-P, Preitner F, Samec S et al. (1997) Targeted gene disruption reveals a leptin-independent role for the mouse $\beta 3$-adrenoceptor in the regulation of body composition. J Clin Invest 100: 1098-11106

111. Enerback S, Jacobsson A, Simpson EM et al. (1997) Mice lacking mitochondrial uncoupling protein are cold-sensitive but not obese. Nature 387: 90-99

112. Strosberg AD, Issad T (1999) The involvement of leptin in humans revealed by mutations in leptin and leptin receptor genes. Trends Pharmacol Sci 20: 227-230

113. Gu W, Tu Z, Kleyn PW, Kissebah A et al. (1999) Identification and functional analysis of novel human melanocortin-4 receptor varients. Diabetes 48: 635-639
114. Krude H, Biebermann H, Luck W, Horn R, Brabant G, Gruters A (1998) Severe early-onset obesity, adrenal insufficiency and red hair pigmentation caused by POMC mutations in humans. Nat Genet 19: 155-157

115. Walston J, Siver K, Boagardus C et al. (1995) Time of onset of non-insulin-dependent diabetes mellitus and genetic variation in the $\beta 3$-adrenergic receptor gene. $\mathrm{N}$ Engl J Med 333: 343-347

116. Widen E, Letto M, Kanninen T, Walston J, Shuldiner AR, Groop LC (1995) Association of a polymorphism in the $\beta 3$-adrenergic receptor gene with features of the insulin resistance syndrome in Finns. $\mathrm{N}$ Engl $\mathrm{J}$ Med 333: $348-351$

117. Clement K, Vaisse C, Manning BSJ et al. (1995) Genetic variation in the $\beta 3$-adrenergic receptor and an increased capacity to gain weight in patients with morbid obesity. N Engl J Med 333: 352-354

118. Yoshida T, Sakane N, Umekawa T, Sakai Y, Takahashi T, Kondo M (1995) Mutation of $\beta 3$-adrenergic receptor gene and response to treatment of obesity. Lancet 46: 1433-1434

119. Sakane N, Yoshida T, Umekawa T, Kogure A, Takakura Y, Kondo M (1997) Effects of Trp64Arg mutation in the $\beta 3$-adrenergci receptor gene on weight loss, body fat distribution, glycemic control, and insulin resistance in obese type 2 diabetic patients. Diabetes Care 20: 1887-1890

120. Kadowaki H, Kosaka K, Yamada N et al. (1995) A mutation in the $\beta 3$-adrenergic receptor gene is associated with obesity and hyperinsulinemia in Japanese subjects. Biochem Biophys Res Commun 215: 555-560

121. Fujisawa T, Ikegami H, Kawaguchi Y, Ogihara T (1998) Meta-analysis of the association of Trp64Arg polymorphism of $\beta 3$-adrenergic receptor gene with body mass index. J Clin Endocrinol Metabo 83: 2441-2444

122. Umekawa T, Yoshida T, Sakane N, Kogure A, Kondo M, Honjyo H (1999) Trp64Arg mutation of $\beta 3$-adrenoceptor gene deteriorates lipolysis induced by $\beta 3$-adrenoceptor agonist in human omental adipocytes. Diabetes 48: $117-120$

123. Arner P, Hoffstedt J (1999) Adrenoceptor genes in human obesity. J Intern Med 245: 667-672

124. Weyer C, Tataranni PA, Snitker S, Danforth E Jr, Ravus$\sin \mathrm{E}$ (1998) Increase in insulin action and fat oxidation after treatment with CL316,243, a highly selective $\beta 3$ adrenoceptor agonist in humans. Diabetes 47: 1555-1561

125. Large V, Hellstrom L, Reynisdottir S et al. (1997) Human beta-2 adrenoceptor gene polymorphisms are highly frequent in obesity and associated with altered adipocyte beta-2 adrenoceptor function. J Clin Invest 100: 3005-3013 